\title{
eHealth cognitieve gedragstherapie voor patiënten met chronische somatische aandoeningen
}

\author{
S. van Beugen,${ }^{1,2}$ H. van Middendorp, ${ }^{1,2}$ R. van der Vaart, ${ }^{1}$ M. Ferwerda,${ }^{1,2}$ A.W.M. Evers ${ }^{1,2}$
}

\begin{abstract}
Veel patiënten met chronische somatische aandoeningen ervaren op zowel lichamelijk als psychologisch gebied beperkingen in het dagelijks leven. Een manier om patiënten hierbij te ondersteunen is het aanbieden van online zorgprogramma's op basis van cognitieve gedragstherapie (eHealth cognitieve gedragstherapie; eCGt). Hoewel uit eerder onderzoek al is gebleken dat eCGt effectief kan zijn bij het verminderen van bijvoorbeeld depressieve klachten in het algemeen, loopt het onderzoek bij patiënten met chronische somatische aandoeningen daarbij nog wat achter. In de laatste jaren is er echter een toenemend aantal studies verschenen die de effectiviteit van eCGt bij diverse chronische somatische aandoeningen hebben onderzocht. Om de overkoepelende resultaten van deze studies te kunnen evalueren is er een meta-analyse uitgevoerd, waarvan de resultaten in dit artikel worden besproken. Hieruit blijkt dat eCGt ook bij chronische somatische aandoeningen effectief is, met kleine tot middelgrote effecten. Grote effecten werden soms gevonden bij ziektespecifieke klachten zoals symptomen van de aandoening en ziektespecifieke kwaliteit van leven. Ook werd gevonden dat een langere behandelduur enigszins samenhing met een grotere afname van depressieve klachten. In aanvulling op de resultaten van de meta-analyse wordt in dit artikel een overzicht gegeven van de recente literatuur over enkele klinisch relevante eCGt onderwerpen: kosteneffectiviteit, begeleiding versus zelfhulp, de rol van behandelduur, en optimaal ontwerp en implementatie van interventies.
\end{abstract}

Trefwoorden: eHealth, internet, CGt, eCGt, review, meta-analyse, chronische somatische aandoeningen

\section{INLEIDING}

Cognitieve gedragstherapie (CGt) wordt op grote schaal gebruikt in de klinische praktijk als effectieve behandelmethode voor psychologische klachten. ${ }^{1}$ In cognitieve gedragstherapie wordt iemand geleerd om zijn gedachten en gedrag te veranderen, waarmee de daarmee gepaard gaande negatieve gevoelens en klachten verminderen. ${ }^{1}$ CGt wordt ook steeds vaker ingezet om het groeiende aantal patiënten met chronische somatische aandoeningen te ondersteunen, bijvoorbeeld door mensen met pijngerelateerde aandoeningen beter te leren omgaan met pijn en beperkingen, of door veelvoorkomende bijkomende stemmings- of vermoeidheidsklachten te behandelen bij mensen met reuma, diabetes of kanker. ${ }^{1-6}$ Hoewel uit onderzoek blijkt dat CGt ook effectief kan zijn

\footnotetext{
${ }^{1}$ Universiteit Leiden, Instituut Psychologie, Sectie Gezondheids-, Medische en Neuropsychologie, Faculteit der Sociale Wetenschappen, Leiden

${ }^{2}$ Radboud universitair medisch centrum, afdeling Medische Psychologie, Nijmegen
}

bij deze patiëntgroepen, is het tot op heden nog niet op grote schaal geïmplementeerd, gedeeltelijk vanwege het gebrek aan CGt-therapeuten gespecialiseerd in de behandeling van deze patiënten. Daarnaast kunnen patiënten lichamelijke beperkingen hebben waardoor het lastig voor ze is om naar een ziekenhuis te komen voor reguliere CGt. Een mogelijke oplossing hiervoor is het aanbieden van CGt via het internet: eHealth cognitieve gedragstherapie (eCGt). Deze therapie wordt vaak aangeboden in de vorm van een online zelfhulpprogramma, begeleid door een behandelaar die feedback geeft en vragen beantwoordt. ${ }^{7}$ Elementen die in face-to-face CGt worden gebruikt, zoals cognitieve herstructurering, psycho-educatie, probleemoplossend denken, ontspanningsoefeningen en stressmanagement, worden in deze programma's online aangeboden. eCGt heeft potentiële voordelen voor zowel patiënten als voor behandelaren, bijvoorbeeld op het gebied van gebruiksgemak, flexibiliteit en vermindering van (reis)kosten en wachtlijsten. ${ }^{8}$ Het veld van eCGt is breed, variërend van begeleide eHealth zelfmanagement interventies waarbij een ge- 
structureerde behandeling doorlopen wordt met minimale begeleiding, tot psychotherapeutische behandelingen op maat met relatief veel begeleiding.

Internetinterventies zoals eCGt blijken in het algemeen effectief te zijn voor diverse psychologische klachten. ${ }^{9-18}$ Steeds meer studies laten zien dat internetinterventies ook effectief kunnen zijn voor psychologische en lichamelijke klachten bij mensen met gezondheidsproblemen ${ }^{19-24}$ en in het bevorderen van gezondheidsgedrag, zoals meer bewegen en gezonder eten. ${ }^{25,26}$ Om te onderzoeken of eCGt eveneens effectief is bij chronische somatische aandoeningen, moeten de resultaten van het toenemende aantal recente studies systematisch geëvalueerd en kwantitatief geanalyseerd worden. Daarnaast is het belangrijk om inzicht te krijgen in welke problematiek aangepakt kan worden met eCGt, bijvoorbeeld door te kijken naar welke soort klachten specifiek verbeteren als gevolg van eCGt. Onderzoek naar effectieve interventie-elementen is eveneens belangrijk, zodat behandelingen op maat aangeboden kunnen worden in de klinische praktijk. De duur van eCGt zou bijvoorbeeld gerelateerd kunnen zijn aan behandeluitkomsten: hoewel er aanwijzingen zijn dat een langere behandelduur gerelateerd is aan betere uitkomsten in patiënten met depressieve symptomen ${ }^{15}$ is de rol van behandelduur nog niet onderzocht bij patiënten met chronische somatische aandoeningen. Ook de mate van begeleiding door een behandelaar kan van invloed zijn; uit eerder onderzoek is gebleken dat begeleide eCGt interventies -waarbij patiënten meestal door een therapeut of coach feedback en ondersteuning ontvangen via online berichten- over het algemeen grotere effecten sorteren dan onbegeleide eCGt interventies. ${ }^{17,27} \mathrm{Om}$ heterogene resultaten te voorkomen en om de vergelijking met face-to-face CGt te optimaliseren, beperkte deze review zich tot begeleide interventies, met als doelstelling het beschrijven van begeleide eCGt behandelingen die onderzocht zijn in gerandomiseerde gecontroleerde studies en het evalueren van hun effectiviteit. Daarnaast wordt de rol van behandelduur bij behandeleffectiviteit onderzocht (noot a). Als aanvulling op deze meta-analyse wordt een overzicht gegeven van de literatuur over relevante klinische aspecten, zoals de kosten, de rol van begeleiding en behandelduur, en de waarde van een gedegen implementatie van eHealth interventies om aan te geven wat er van belang is voor optimaal gebruik van eHealth in de klinische praktijk.

\section{MeTHOdE}

De databases PubMed, PsycINFO en Embase werden doorzocht tot februari 2012, met een combinatie van zoektermen op het gebied van effectstudies, internet en CGt. ${ }^{28}$ De inclusiecriteria waren: (1) gerandomiseerde gecontroleerde Studie (RCT), (2) behandeling primair via het internet aangeboden, (3) behandeling gebaseerd op CGtprincipes, waarbij in ieder geval een minimale vorm van cognitieve (bijvoorbeeld cognitieve herstructurering en probleemoplossend denken) en gedragsmatige technieken (bijvoorbeeld exposure en gedragsexperimenten) zijn gebruikt. (4) behandeling begeleid door een behandelaar, met minimaal 1 behandeling-gerelateerd contactmoment, en (5) volwassen patiënten (leeftijd $\geq 18$ jaar) met een chronische lichamelijke aandoening. ${ }^{29}$ De zoekstrategie leverde 4848 unieke referenties op, waarvan 23 voldeden aan de inclusiecriteria $^{30-52}$ (zie Tabel 1 voor een overzicht van geincludeerde studies). Deze studies includeerden 4340 proefpersonen (2299 eCGt en 2041 controle).

De effectiviteit van eCGt behandelingen werd geëvalueerd op basis van drie categorieën van uitkomstmaten: (1) generieke psychologische uitkomstmaten zoals depressieve klachten en angstklachten, (2) ziektegerelateerde lichamelijke uitkomstmaten zoals pijnklachten of vermoeidheid, en (3) uitkomstmaten met betrekking tot de impact van de aandoening op het dagelijks leven, zoals ziektespecifieke kwaliteit van leven of ziektespecifieke distress.

Als maat van effectgrootte werd het gestandaardiseerde gemiddeld verschil (SMD) berekend voor elke uitkomstmaat, door het verschil in gemiddeldes van de eCGt af te trekken van het verschil in gemiddeldes van de controlegroep en deze score te delen door de gepoolde standaarddeviatie. ${ }^{53}$ Effectgroottes van 0,2 , 0,5, en 0,8 kunnen beschouwd worden als klein, middelgroot en groot. ${ }^{54}$ Heterogeniteit in de analyses werd beoordeeld door middel van Higgins $I^{2}$, een maat die aangeeft in welke mate studies onderling niet vergelijkbaar (inconsistent) zijn. ${ }^{55}$ Waardes van $25 \%$, 50\% en $75 \%$ kunnen respectievelijk worden beschouwd als lage, gemiddelde en hoge heterogeniteit. SMD's werden berekend in 'random effects' modellen. ${ }^{56}$ Voor een uitgebreide beschrijving van zoekstrategieën, inclusiecriteria en methodologie, inclusief het proces van studiebeoordeling en risk of bias, verwijzen we naar een eerdere Engelstalige publicatie over deze meta-analyse. ${ }^{28}$

\section{RESULTATEN}

\section{Chronische somatische aandoeningen}

De aandoeningen die onderzocht werden waren chronische pijn ( $n=5$ studies), hoofdpijn of migraine $(n=4)$, 
Tabel 1. eCGt bij chronische somatische aandoeningen: overzicht geïncludeerde studies

\begin{tabular}{|c|c|c|c|c|}
\hline Studie, Publicatiejaar & Aandoening & Condities, $\mathbf{N}$ & Dropout & Interventieduur \\
\hline Abbott et al.,2009 & Tinnitus & $\begin{array}{l}\text { eCGt, } 32 \\
\text { Online psychoeducatie, } 24\end{array}$ & $\begin{array}{l}\text { Interventie } 23 / 32(72 \%) \\
\text { Metingen } 32 / 56(57 \%)\end{array}$ & 6 weken \\
\hline Andersson et al.,2002 & Tinnitus & $\begin{array}{l}\text { eCGt, } 53 \\
\text { Wachtlijst, } 64\end{array}$ & $\begin{array}{l}\text { Interventie } 26 / 53(49 \%) \\
\text { Metingen } 45 / 117(38 \%)\end{array}$ & 6 weken \\
\hline Andersson et al.,2003 & Chronische hoofdpijn & $\begin{array}{l}\text { eCGt + wekelijks telefonisch } \\
\text { contact, } 24 \\
\text { eCGt, } 20\end{array}$ & $\begin{array}{l}\text { Interventie } 7 / 24 \text { (29\%) } \\
\text { Metingen } 20 / 44 \text { (45\%) }\end{array}$ & 6 weken \\
\hline van Bastelaar et al.,2011 & $\begin{array}{l}\text { Diabetestype } 1 \text { en } 2 \text {, } \\
\text { depressieve klachten }\end{array}$ & $\begin{array}{l}\text { eCGt, } 125 \\
\text { Wachtlijst, } 130\end{array}$ & $\begin{array}{l}\text { Interventie } 72 / 125(58 \%) \\
\text { Metingen } 88 / 255(35 \%)\end{array}$ & 8 weken \\
\hline Berman et al.,2009 & Chronische pijn & $\begin{array}{l}\text { eCGt, } 52 \\
\text { Wachtlijst, } 37\end{array}$ & $\begin{array}{l}\text { Interventie } 10 / 52(19 \%) \\
\text { Metingen } 11 / 89(12 \%)\end{array}$ & 6 weken \\
\hline Brattberg,2006 & $\begin{array}{l}\text { Chronische pijn en/of } \\
\text { burnout }\end{array}$ & $\begin{array}{l}\text { eCGt, } 30 \\
\text { Wachtlijst, } 30\end{array}$ & $\begin{array}{l}\text { Interventie } 3 / 30(10 \%) \\
\text { Metingen } 5 / 60(8 \%)\end{array}$ & 20 weken \\
\hline Buhrman et al.,2004 & Chronische rugpijn & $\begin{array}{l}\text { eCGt, } 22^{a} \\
\text { Wachtlijst, } 29^{a}\end{array}$ & $\begin{array}{l}\text { Interventie: niet gerapporteerd } \\
\text { Metingen } 5 / 56(9 \%)\end{array}$ & 6 weken \\
\hline Buhrman et al.,2011 & Chronische rugpijn & $\begin{array}{l}\text { eCGt, } 26 \\
\text { Wachtlijst, } 28\end{array}$ & $\begin{array}{l}\text { Interventie } 3 / 26(12 \%) \\
\text { Metingen } 4 / 54(7 \%)\end{array}$ & 8 weken \\
\hline David et al.,2011 & Borstkanker & $\begin{array}{l}\text { eCGt, } 69 \\
\text { Wachtlijst, } 64\end{array}$ & $\begin{array}{l}\text { Interventie } 37 / 69(54 \%) \\
\text { Metingen } 63 / 133(47 \%)\end{array}$ & 8 weken \\
\hline $\begin{array}{l}\text { Devineni \& } \\
\text { Blanchard,2005 }\end{array}$ & Chronische hoofdpijn & $\begin{array}{l}\text { eCGt, } 39^{\mathrm{a}} \\
\text { Wachtlijst, } 47^{\mathrm{a}}\end{array}$ & $\begin{array}{l}\text { Interventie: niet gerapporteerd } \\
\text { Metingen } 53 / 139(38 \%)\end{array}$ & 4 weken \\
\hline Ghahari et al.,2010 & $\begin{array}{l}\text { Vermoeidheid bij neuro- } \\
\text { logische aandoeningen }\end{array}$ & $\begin{array}{l}\text { eCGt, } 34 \\
\text { Online zelfmanagement, } 28 \\
\text { Reguliere zorg, } 33\end{array}$ & $\begin{array}{l}\text { Interventie } 10 / 34(29 \%) \\
\text { Metingen } 10 / 95(11 \%)\end{array}$ & 7 weken \\
\hline Hedborg \& Muhr,2011 & Migraine & $\begin{array}{l}\text { eCGt, } 28 \\
\text { eCGt }+ \text { handmassage, } 27 \\
\text { Controle, } 28\end{array}$ & $\begin{array}{l}\text { Interventie } 6 / 55(11 \%) \\
\text { Metingen } 7 / 83(8 \%)\end{array}$ & 26 weken \\
\hline Hesser et al.,2012 & Tinnitus & $\begin{array}{l}\text { eCGt, } 32 \\
\text { eACT, } 35 \\
\text { Online discussieforum, } 32\end{array}$ & $\begin{array}{l}\text { Interventie } 10 / 67(15 \%) \\
\text { Metingen } 4 / 99(4 \%)\end{array}$ & 8 weken \\
\hline Hunt et al.,2009 & PDS & $\begin{array}{l}\text { eCGt, } 28 \\
\text { Wachtlijst + zelfmonitoring, } 26\end{array}$ & $\begin{array}{l}\text { Interventie } 15 / 28(54 \%) \\
\text { Metingen } 23 / 54(43 \%)\end{array}$ & 6 weken \\
\hline Kaldo et al.,2008 & Tinnitus & $\begin{array}{l}\text { eCGt, } 26 \\
\text { Face-to-face CGt groep, } 25\end{array}$ & $\begin{array}{l}\text { Interventie } 10 / 26(38 \%) \\
\text { Metingen } 2 / 51(4 \%)\end{array}$ & 6 weken \\
\hline Ljótsson et al.,2010 & PDS & $\begin{array}{l}\text { eCGt, } 43 \\
\text { Wachtlijst \& discussieforum, } 43\end{array}$ & $\begin{array}{l}\text { Interventie } 13 / 43(30 \%) \\
\text { Metingen } 5 / 86(6 \%)\end{array}$ & 10 weken \\
\hline Ljótsson et al.,2011 & PDS & $\begin{array}{l}\text { eCGt, } 30 \\
\text { Wachtlijst \& discussieforum, } 31\end{array}$ & $\begin{array}{l}\text { Interventie } 7 / 30(23 \%) \\
\text { Metingen } 11 / 61(18 \%)\end{array}$ & 10 weken \\
\hline Ljótsson et al.,2011 & PDS & $\begin{array}{l}\text { eCGt met exposure elementen, } 98 \\
\text { Online stressmanagement zonder } \\
\text { exposure, } 97\end{array}$ & $\begin{array}{l}\text { Interventie 1/98 (1\%) } \\
\text { Metingen 4/195 (2\%) }\end{array}$ & 10 weken \\
\hline Lorig et al.,2006 & $\begin{array}{l}\text { Heterogene } \\
\text { patiëntgroep }\end{array}$ & $\begin{array}{l}\text { eCGt, } 457 \\
\text { Reguliere zorg, } 501\end{array}$ & $\begin{array}{l}\text { Interventie } 104 / 457(23 \%) \\
\text { Metingen } 175 / 958(18 \%)\end{array}$ & 6 weken \\
\hline Lorig et al.,2008 & Artritis of fibromyalgie & $\begin{array}{l}\text { eCGt, } 433 \\
\text { Reguliere zorg, } 422\end{array}$ & $\begin{array}{l}\text { Interventie } 123 / 433(28 \%) \\
\text { Metingen } 214 / 855(25 \%)\end{array}$ & 6 weken \\
\hline Lorig et al.,2010 & Diabetes type 2 & $\begin{array}{l}\text { eCGt, } 259 \\
\text { eCGt + emailcontact, } 232 \\
\text { Reguliere zorg, } 270\end{array}$ & $\begin{array}{l}\text { Interventie 96/491 (20\%) } \\
\text { Metingen 116/761 (15\%) }\end{array}$ & 6 weken \\
\hline Ström et al.,2000 & Chronische hoofdpijn & $\begin{array}{l}\text { eCGt, } 20^{\mathrm{a}} \\
\text { Wachtlijst, } 25^{\mathrm{a}}\end{array}$ & $\begin{array}{l}\text { Interventie: niet gerapporteerd } \\
\text { Metingen } 57 / 102(56 \%)\end{array}$ & 6 weken \\
\hline Thompson et al.,2010 & $\begin{array}{l}\text { Epilepsie, depressieve } \\
\text { klachten }\end{array}$ & $\begin{array}{l}\text { eCGt, } 13 \\
\text { eCGt telefonisch, } 12 \\
\text { Reguliere zorg + wachtlijst, } 27\end{array}$ & $\begin{array}{l}\text { Interventie } 7 / 26(27 \%) \\
\text { Metingen } 13 / 52(52 \%)\end{array}$ & 8 weken \\
\hline
\end{tabular}

a aantallen na dropout; cijfers vóór dropout waren niet gerapporteerd

Afkortingen: PDS = prikkelbare darm syndroom, $\mathrm{KvL}=$ kwaliteit van leven, eCGt = eHealth cognitieve gedragstherapie, eACT = eHealth acceptance and commitment therapie

tinnitus $(n=4)$, prikkelbare darm syndroom (PDS; $n=4)$, diabetes $(n=2)$, borstkanker $(n=1)$, epilepsie $(n=1)$, vermoeidheid bij patiënten met chronische neurologische aandoeningen $(n=1)$ en een heterogene patiëntgroep $(n=1)$ (zie Tabel 1). De overgrote meerderheid van de studies $(n=20)$ werd uitgevoerd binnen de algemene populatie, waarbij deelnemers geworven werden via bijvoorbeeld advertenties of patiëntverenigingen. De gemiddelde leeftijd van de proefpersonen binnen studies varieerde tussen 34 en 66 jaar; de meeste studies bevatten meer vrouwelijke dan mannelijke proefpersonen.

\section{eCGt behandelingen}

Interventies bestonden uit een variatie aan generieke CGt-technieken, vaak aangevuld met specifieke technieken die geschikt waren voor de aandoening die onderzocht werd, zoals bijvoorbeeld het aanbieden van ruisgeluiden bij tinnitusklachten. ${ }^{43}$ De meerderheid van de studies beschreef de interventies als gestructureerde modulaire zelfhulpprogramma's met minimale begeleiding waarbij de patiënt wekelijks een module doorliep. De interventiecomponenten die het vaakst voorkwamen in de studies waren cognitieve therapietechnieken, ontspanningsoefeningen en het verbeteren van copingvaardigheden. Deze componenten werden in $74-100 \%$ van de 
studies genoemd. Stressmanagement en gedragstherapietechnieken werden genoemd in meer dan de helft van de studies. Andere behandelcomponenten, die in $26-35 \%$ van de interventies verwerkt waren, waren het aanleren van probleemoplossende vaardigheden, mindfulnesstechnieken, exposure, en lichaamsbeweging. De meerderheid van de interventies werd omschreven als CGt en/ of zelfmanagement, en enkele studies waren gebaseerd op bijvoorbeeld acceptatiegerichte technieken, waarbij aandacht voor het leven in het hier en nu zonder te oordelen centraal staat (bijvoorbeeld acceptance and commitment therapie (ACT), ${ }^{41}$ exposurebehandeling in combinatie met mindfulness-technieken, ${ }^{4-46}$ of aandachtgerichte cognitieve therapie (mindfulness-based cognitive therapy $\left.(\mathrm{MBCT})^{51}\right)$ ). Interventies waren over het algemeen breed opgezet. Incidenteel kwam het voor dat er een specifiek behandeldoel beschreven werd, bijvoorbeeld het verminderen van depressieve klachten, ${ }^{51,52}$ distress gerelateerd aan de aandoening, ${ }^{30,32}$ of symptomen van de aandoening. ${ }^{36,38,44}$ Maar ook in de interventies met een meer specifiek behandeldoel waren de interventiecomponenten vaak zo opgezet dat ze breder toepasbaar waren.

\section{Behandelcontact en dropout}

Alle interventies boden mogelijkheden tot contact met een behandelaar, meestal in de vorm van (wekelijks) e-mailcontact met geregistreerde klinisch psychologen of gesuperviseerde masterstudenten Psychologie. Eén studie was puur gebaseerd op behandelcontact via e-mail, zonder verdere online behandelcomponenten. ${ }^{37}$ In drie van de 23 studies was telefonisch contact de voornaamste contactmogelijkheid. Vijf studies boden de inhoud van de interventie groepsgewijs aan via een besloten online groepsomgeving (bijvoorbeeld een online forum), waarbij de patiënten aangemoedigd werden om op de opdrachten en elkaar te reageren en waarbij feedback van de behandelaren ook op het forum werd gegeven. Daarnaast maakten tien studies gebruik van een online forum als een extra behandelcomponent, wat patiënten in staat stelde om met elkaar te communiceren als aanvulling op de individuele eCGt interventie.

De mate van dropout varieerde, maar was over het algemeen vrij hoog (mediaan 18\%, spreidingsbreedte 2-57\%), vooral in de eCGt groepen (mediaan 29\%, spreidingsbreedte 1-72\%). In vijf studies werden redenen gerapporteerd voor dropout; de meest genoemde reden in deze studies was een gebrek aan tijd.

\section{Effectiviteit van eCGt interventies}

Een overzicht van de gepoolde effectgroottes (SMD's) bij psychologische, lichamelijke en impactgerelateerde uitkomstmaten is te vinden in Tabel 2. In vijf van de 16 studies die generieke psychologische uitkomstmaten onderzochten werd een significant effect gevonden. De gepoolde effectgrootte was klein maar significant voor depressieve klachten en angstklachten, en klein en marginaal significant voor generieke distress (zie Tabel 2).

In tien van de zeventien studies die ziektegerelateerde lichamelijke uitkomstmaten onderzochten werd een significant effect gevonden. Er was veel variatie in gepoolde effectgroottes voor lichamelijke uitkomstmaten; grote effecten werden gevonden voor symptomen van het prikkelbare darm syndroom, middelgrote effecten voor hoofdpijn, kleine effecten voor pijn en vermoeidheid, en geen statistisch significante effecten voor tinnitus luidheid, slaapkwaliteit en glycemiecontrole (zie Tabel 2).

In zeven van de negen studies die ziektegerelateerde distress of ziektegerelateerde kwaliteit van leven onderzochten werd een significant effect gevonden. Er werden kleine maar significante effecten gevonden op ziektegerelateerde distress en grote effecten op ziektegerelateerde kwaliteit van leven (zie Tabel 2).

Wanneer eCGt vergeleken werd met andere behandelcondities, zoals bijvoorbeeld face-to-face CGt, werden over het algemeen vergelijkbare effecten gevonden tussen de condities. ${ }^{28}$

\section{De rol van behandelduur}

De meeste interventies waren relatief kort, met weinig variatie in behandelduur: van de 23 studies duurde er één vier weken, elf zes weken, en eveneens elf zeven tot 26 weken (zie Tabel 1). Daarom werden interventies die zes weken of korter duurden vergeleken met interventies die zeven weken of langer duurden. De rol van behandelduur

Tabel 2. Gepoolde effectgroottes voor eCGt in vergelijking met passieve controlecondities

\begin{tabular}{|c|c|c|c|c|c|c|}
\hline Uitkomstmaten & $k^{\mathrm{a}}$ & SMD $^{\mathbf{b}}$ & $95 \% \mathrm{BI}$ & $z$ & $p$ & $I^{2}(\%)$ \\
\hline \multicolumn{7}{|l|}{ Generiek psychologisch } \\
\hline Depressieve klachten & 15 & 0,21 & $0,08-0,34$ & 3,18 & 0,001 & 29 \\
\hline Angstklachten & 10 & 0,17 & $0,01-0,32$ & 2,14 & 0,03 & 0 \\
\hline Generieke distress & 6 & 0,21 & $0,00-0,41$ & 1,98 & 0,05 & 0 \\
\hline \multicolumn{7}{|l|}{ Ziektegerelateerd lichamelijk } \\
\hline PDS-symptomen & 2 & 1,19 & $0,82-1,57$ & 6,25 & $<0,001$ & 0 \\
\hline Hoofdpijn & 3 & 0,49 & $0,21-0,77$ & 3,41 & $<0,001$ & 0 \\
\hline Slaapkwaliteit & 3 & 0,25 & $-0,02-0,53$ & 1,80 & 0,07 & 0 \\
\hline Pijn & 6 & 0,18 & $0,08-0,28$ & 3,61 & $<0,001$ & 0 \\
\hline Vermoeidheid & 2 & 0,15 & $0,05-0,26$ & 2,87 & $<0,01$ & 0 \\
\hline Tinnitus luidheid & 2 & $-0,04$ & $-0,40-0,32$ & 0,24 & 0,81 & 0 \\
\hline Glycemiecontrole & 2 & 0,07 & $-0,17-0,30$ & 0,54 & 0,59 & 62 \\
\hline \multicolumn{7}{|l|}{ Ziektegerelateerd impact } \\
\hline Ziektespecifieke KvL & 3 & 1,11 & $0,79-1,44$ & 6,73 & $<0,001$ & 0 \\
\hline Ziektespecifieke distress & 6 & 0,17 & $0,03-0,31$ & 2,41 & 0,02 & 57 \\
\hline
\end{tabular}

${ }^{\mathrm{a}} \mathrm{k}=$ aantal vergelijkingen

${ }^{b} \mathrm{SMD}=$ gestandaardiseerde gemiddeld verschil

Afkortingen: $\mathrm{BI}=$ betrouwbaarheidsinterval; PDS = prikkelbare darm syndroom; $\mathrm{KvL}=$ kwaliteit van leven 
bleek van belang bij depressieve klachten: vier van de vijf studies die een significant effect op depressieve klachten vonden, hadden een interventieduur van zeven weken of langer. Effectgroottes van de langere interventies $(n=8$; $\mathrm{SMD}=0,29 ; 95 \% \mathrm{BI}=0,13-0,46)$ waren groter dan de effectgroottes in de kortere interventies $(n=7 ; \mathrm{SMD}=0,08$; $95 \% \mathrm{BI}=-0,05-0,22)\left(\chi_{1}^{2}=3,91, p=0,05\right)$. Interventieduur leek geen invloed op effectiviteit te hebben bij andere klachten, hoewel er vaak te weinig studies per klacht waren om dit goed te kunnen beoordelen.

\section{DISCUSSIE}

\section{Effectiviteit}

De resultaten van deze meta-analyse lieten zien dat eCGt werkzaam kan zijn bij chronische somatische aandoeningen voor zowel psychologische klachten zoals depressie- en angstklachten, als voor meer ziektespecifieke klachten zoals symptomen van de aandoening en een verlaagde kwaliteit van leven. De effecten waren klein tot middelgroot, waarbij grotere effecten soms gevonden werden voor ziektespecifieke uitkomstmaten. Enkele studies lieten zien dat eCGt even effectief was als andere behandelingen, zoals face-to-face CGt. Deze resultaten onderstrepen het belang van onderzoek naar de werkzame componenten van eCGt, ook gezien de variatie in gebruikte behandeltechnieken en de verschillen in duur en vorm van de begeleiding. De rol van één component, namelijk behandelduur, werd onderzocht in deze metaanalyse, waaruit bleek dat interventies met een duur langer dan 6 weken resulteerden in grotere verbeteringen in depressieve klachten.

De resultaten van deze review zijn vergelijkbaar met eerdere reviews en meta-analyses die kleine tot middelgrote effecten vonden bij psychologische klachten, ${ }^{9-18}$ voor patiënten met gezondheidsproblemen ${ }^{19-24,57}$ en voor face-to-face CGt. ${ }^{1,58,59}$ Nieuw in onze review is dat we ook de meer recente studies meenamen, de rol van behandelduur onderzochten en verschillen in effectiviteit voor specifieke categorieën van uitkomstmaten lieten zien. Met deze aanpak werd aangetoond dat begeleide eCGt effectief kan zijn bij psychologische en lichamelijke klachten bij mensen met chronische somatische aandoeningen, en hen kan ondersteunen bij het leren omgaan met de gevolgen van hun aandoening in het dagelijks leven. Het is echter niet alleen van belang om te weten of behandelingen effectief zijn, zoals onderzocht in deze meta-analyse, maar bijvoorbeeld ook of behandelingen kosteneffectief zijn, in hoeverre en door wie interventies begeleid zouden moeten worden, hoe lang de behandeling zou moeten duren en hoe een behandeling optimaal geïmplementeerd kan worden in de praktijk. In onderstaand overzicht wordt ingegaan op wat er bekend is uit de recente literatuur over deze klinisch relevante onderwerpen op het gebied van eCGt.

\section{Kosteneffectiviteit}

Eén van de meest genoemde voordelen van eCGt interventies is hun kosteneffectiviteit. Terwijl in een review uit 2009 nog vastgesteld werd dat daar nog maar beperkte evidentie voor was, ${ }^{60}$ is er in de laatste vijf jaar veel vooruitgang geboekt op dit gebied. Recente systematische reviews lieten zien dat eCGt interventies kosteneffectief kunnen zijn in vergelijking met reguliere zorg en face-toface CGt. ${ }^{14,61}$ Specifiek voor chronische somatische aandoeningen is de kosteneffectiviteit onder andere onderzocht bij het prikkelbare darm syndroom, ${ }^{44,62}$ pijn ${ }^{63}$ tinnitus ${ }^{64}$ en vermoeidheid bij multiple sclerose. ${ }^{65}$ Deze studies lieten onder meer zien dat eCGt minder tijd van de behandelaar kost dan face-to-face behandeling ${ }^{64}$ en dat zowel de directe kosten ${ }^{65}$ als de maatschappelijke kosten lager zijn, ${ }^{44,62}$ bijvoorbeeld door een vermindering in arbeidsverzuim. ${ }^{62}$

\section{Begeleide interventies versus zelfhulp}

eCGt interventies bestaan in verschillende vormen en maten. Een belangrijk aspect waarop interventies kunnen verschillen is de begeleiding, die kan variëren van actieve betrokkenheid van een therapeut via face-to-face gesprekken of online berichten tot zelfhulpinterventies zonder persoonlijk contact. Meta-analyses over eCGt bij depressieve klachten lieten zien dat begeleide interventies leidden tot middelgrote tot grote verminderingen in depressieve klachten, terwijl onbegeleide zelfhulpprogramma's leidden tot kleine verminderingen. ${ }^{17,27,66}$ Of dit ook het geval is bij patiënten met chronische somatische aandoeningen moet nog onderzocht worden.

Hoewel eCGt interventies in onderzoeken veelal begeleid worden door psychologen (in opleiding), laten nieuwe inzichten zien dat de begeleiding van geprotocolleerde interventies niet noodzakelijk gedaan hoeft te worden door een klinisch opgeleide therapeut; in eerdere studies onder patiënten met gegeneraliseerde angststoornis of sociale fobie werd bijvoorbeeld aangetoond dat begeleiding door een niet-therapeutisch opgeleid persoon onder supervisie van een therapeut even effectief kan zijn als begeleiding door een therapeut. ${ }^{67,68}$ Ook als de begeleiding niet door een getrainde therapeut wordt gedaan brengen begeleide interventies logischerwijs meer kosten met zich mee dan onbegeleide zelfhulpprogramma's. Wanneer eCGt interventies echter vergeleken worden met face-to-face CGt interventies, zien we dat de tijdsbesteding van een behandelaar aan een patiënt in een eCGt behandeling beduidend korter is, ${ }^{61}$ terwijl over het algemeen vergelijkbare effecten worden gevonden. ${ }^{11,28,61}$ Samenvattend lijkt begeleide eCGt qua effectiviteit doeltreffender te zijn dan onbegeleide zelfhulp, waarbij begeleide interventies wel een grotere (tijds)investering vragen. Bij de keuze voor een programma is het raadzaam om rekening te houden met de patiënt als individu; de ernst van de klachten en de zorgbehoefte van de patiënt kunnen daarbij een rol spelen. ${ }^{6,70}$

\section{De rol van behandelduur}

Uit deze review bleek dat een langere interventieduur enigszins samenhing met een sterkere vermindering van depressieve klachten bij patiënten met chronische somatische aandoeningen. Een soortgelijke bevinding werd gedaan in onderzoek naar eCGt bij depressieve klachten. ${ }^{15}$ Hierbij moet opgemerkt worden dat dropout hoger 
was in de langere interventies, wat het belang onderstreept van het onderzoeken en bevorderen van therapietrouw. ${ }^{71}$ Ook bij onderzoek naar face-to-face interventies zijn er aanwijzingen dat een langere behandelduur kan leiden tot grotere effecten bij mensen met depressieve klachten. ${ }^{72}$ Gedetailleerder onderzoek naar optimalisering van de behandelduur is nodig, zodat een optimaal behandeleffect kan worden behaald.

\section{Ontwerp en implementatie}

Om de effectiviteit van eCGt te bevorderen en te verbeteren speelt niet alleen de inhoud van de interventie een belangrijke rol, maar ook de technologie en het gebruik daarvan. Te vaak gebeurt het dat het gebruik van een online interventie na een (geslaagde) pilotfase strandt. Veelvoorkomende oorzaken hiervoor zijn onvoldoende gebruiksgemak voor patiënten, twijfel of motivatiegebrek bij behandelaars en een gebrek aan ondersteuning op managementniveau. ${ }^{73,74}$ Het is belangrijk om te realiseren dat een online behandeling niet simpelweg een vertaling is van een (bestaande) face-to-face behandeling naar een online programma. Door rekening te houden met wensen en vaardigheden van gebruikers (zowel patiënten als behandelaars), beschikbare technologische middelen en implementatie in het huidige zorgproces kan het gebruik en het gebruiksgemak van een online behandeling enorm bevorderd worden, met betere therapietrouw en (kosten)effectiviteit als verwacht resultaat. ${ }^{75} \mathrm{Om}$ dit te bereiken is het belangrijk om de meest belanghebbenden bij elke stap in het ontwikkelingsproces te betrekken; vanaf het eerste moment waarop gebruikerswensen worden geïnventariseerd tot aan het moment waarop de behandeling wordt geëvalueerd (zie bijvoorbeeld de eHealth Roadmap). ${ }^{76,77}$

\section{Blik op de toekomst voor onderzoek en praktijk}

De resultaten van deze review bieden verschillende aangrijpingspunten voor toekomstig eCGT onderzoek, bijvoorbeeld op het gebied van interventiedesign en methodologie. Allereerst blijkt dat er nog maar weinig studies verschenen zijn die de effectiviteit van eCGt interventies bij patiënten met chronische somatische aandoeningen onderzoeken, en veel van deze studies worden uitgevoerd door dezelfde onderzoeksgroepen. Het valt op dat er weinig tot geen eCGt interventies onderzocht worden bij bepaalde veelvoorkomende chronische somatische aandoeningen, zoals hart-, long- en nieraandoeningen. Daarnaast worden er vaak relatief veel vrouwen en weinig oudere mensen geïncludeerd in de studies. Meer studies met representatieve steekproeven die zich richten op een bredere variatie aan chronische somatische aandoeningen, waarbij patiënten langer gevolgd worden, zijn nodig om betrouwbare conclusies te kunnen trekken over (lange termijn-)effecten. Ook op methodologisch gebied zijn er verbeterpunten, met betrekking tot bijvoorbeeld de opzet van studies. ${ }^{28}$ Gezien dropout een bekend probleem is in eCGt onderzoek, ${ }^{70,78}$ is het van belang om manieren te onderzoeken die betrokkenheid van de patiënt bevorderen. Het aanbieden van interventies op maat (tailoring), waarbij aangesloten wordt bij de specifieke behoefte van de individuele patiënt, zou hiervoor een effectieve strategie kunnen zijn. ${ }^{79-81}$ Overige strategieën die uit eerder onderzoek naar voren zijn gekomen om te voorkomen dat patiënten stoppen met een interventie zijn bijvoorbeeld meer contact met een behandelaar, regelmatige website updates en het maken van afspraken over regelmatig (bijvoorbeeld dagelijks, wekelijks) gebruik van de interventie. ${ }^{82,83}$ Daarnaast is het belangrijk dat ook de specifieke werkzame elementen van de interventies worden onderzocht. ${ }^{84}$ Door systematische analyse van gebruikersdata kan het daadwerkelijk gebruik van een interventie verder worden onderzocht, evenals de betrokkenheid van patiënten, de gebruiksvriendelijkheid van programma's en de werkzame elementen. ${ }^{85}$

Naast deze onderzoeksgerichte blik op de toekomst, is het interessant om vooruit te blikken naar de mogelijkheden van toekomstige eCGt interventies in de klinische praktijk. Gezien de snelle vooruitgang in technologische mogelijkheden is te verwachten dat eCGt interventies steeds meer gebruik zullen maken van bijvoorbeeld (video-)chatmogelijkheden en smartphones (mHealth), waarbij ook meer gebruik zal worden gemaakt van (audio)visuele elementen. ${ }^{86}$ Een ander eHealth domein in opkomst is serious gaming, waarbij (computer)spelelementen worden ingezet voor therapeutische doeleinden, bijvoorbeeld om cognitief functioneren te bevorderen of psychologische klachten te verminderen. ${ }^{86}$ Ook zien we steeds meer onderzoeken naar (online) virtual reality interventies, die bijvoorbeeld ingezet kunnen worden voor pijnreductie of exposure bij angsten en fobieën. ${ }^{87}$ Idealiter worden in de toekomst interventies ontwikkeld waarbij elementen op een flexibele manier in- en uitgeschakeld kunnen worden om maatwerk te kunnen leveren, op basis van de specifieke behoeften van patiënten, zowel op het gebied van de inhoudelijke behandeldoelen als op het gebied van technologische mogelijkheden.

\section{CONCLUSIES EN KLINISCHE IMPLICATIES}

Uit de resultaten van deze review blijkt dat eCGt interventies zowel psychologische als ziektegerelateerde lichamelijke klachten kunnen verbeteren in patiënten met chronische somatische aandoeningen. Er worden kleine tot middelgrote effecten gevonden, met soms grotere verbeteringen voor ziektespecifieke klachten. Deze resultaten geven aan dat, hoewel de klinische praktijk zich vaak richt op psychologische aspecten van lichamelijke aandoeningen, behandeling ook zeker gericht kan worden op verbetering van de lichamelijke klachten. Met betrekking tot de behandelduur zien we dat korte behandelingen van 6 weken vaak voorkomen, maar langere behandelingen wellicht effectiever zijn als het gaat om depressieve klachten. Maatwerk met betrekking tot de behandeling en de behandelduur lijkt dan ook geboden. Aangezien veel mensen tussentijds uitvallen, is het in de klinische praktijk eveneens van belang om voldoende aandacht te besteden aan de motivatie van patiënten in online interventies. De literatuur op het gebied van eCGt laat verder zien dat begeleide interventies over het algemeen effectiever zijn dan zelfhulpinterventies zonder begeleiding. Wat minder van 
belang lijkt te zijn is wie die begeleiding verzorgt: uit verschillende studies blijkt dat begeleiding door iemand zonder psychologische opleiding niet onder hoeft te doen voor begeleiding door een getrainde therapeut, indien de interventies geprotocolleerd zijn. Dit biedt mogelijkheden om eCGt interventies op een kosteneffectieve manier aan te kunnen bieden en het bereik van eCGt verder te vergroten. Hoewel er in onderzoek veel interventies zijn ontwikkeld voor deze patiëntgroepen is het bereik van de interventies nog beperkt, omdat de vertaalslag naar de praktijk nog onvoldoende gemaakt wordt. Daarom zullen er in de nabije toekomst stappen gezet moeten worden om effectieve implementatie te bevorderen. Verder onderzoek is nodig naar specifieke werkzame elementen van interventies, om deze behandelingen doelgericht en optimaal in te kunnen zetten.

\section{NOTEN}

a De gerapporteerde resultaten in dit artikel zijn in sterke mate gebaseerd op een eerder verschenen publicatie van deze onderzoeksgroep. ${ }^{28}$

b Deze studie is mede gesubsidieerd door een research grant (WS682746) van Pfizer Inc.

\section{ABSTRACT}

Internet-based cognitive behavioral therapy for patients with chronic somatic conditions

Many patients with chronic somatic conditions regularly experience impairments in physical and psychological functioning in their daily life. A way to support these patients is to offer online programs based on cognitive behavioral therapy (Internet-based cognitive behavioral therapy; ICBT). Although a substantial evidence base already exists regarding the effectiveness of ICBT in treating, for example, depressive symptoms, research on ICBT for chronic somatic conditions is still upcoming. In recent years, a growing number of randomized controlled trials were published that examined the effectiveness of ICBT in various chronic somatic conditions. To systematically and quantitatively evaluate the results of these studies, a metaanalysis was conducted, the results of which are discussed in this article. Results indicated that ICBT is also overall effective for chronic somatic conditions, with small to moderate effect sizes. Larger effects were occasionally found for disease-specific outcomes such as disease symptoms and disease-specific quality of life. A longer treatment duration was found to be marginally related to a larger decrease in depressive symptoms. In addition to the results of the meta-analysis, this article provides an overview of the recent literature regarding several clinically relevant ICBT topics: cost-effectiveness, guided ICBT interventions versus self-help, the role of treatment duration, and optimal design and implementation of eHealth interventions.

Keywords: eHealth, Internet, cognitive behavioral therapy, ICBT, review, meta-analysis, chronic somatic conditions

\section{LITERATUUR}

1. Butler AC, Chapman JE, Forman EM, Beck AT. The empirical status of cognitive-behavioral therapy: a review of meta-analyses. Clin Psychol Rev 2006;26:17-31.

2. Holroyd KA, Nash JM, Pingel JD, Cordingley GE, Jerome A. A comparison of pharmacological (amitriptyline HCL) and nonpharmacological (cognitive-behavioral) therapies for chronic tension headaches. J Consult Clin Psychol 1991;59:387-93.

3. Ismail K, Winkley K, Rabe-Hesketh S. Systematic review and meta-analysis of randomised controlled trials of psychological interventions to improve glycaemic control in patients with type 2 diabetes. Lancet 2004;363:1589-97.

4. Lee YH, Chiou PY, Chang PH, Hayter M. A systematic review of the effectiveness of problem-solving approaches towards symptom management in cancer care. J Clin Nurs 2010;20:73-85.

5. Price JR, Mitchell E, Tidy E, Hunot V. Cognitive behaviour therapy for chronic fatigue syndrome in adults. Cochrane Database Syst Rev 2008: CD001027.

6. Hoffman BM, Papas RK, Chatkoff DK, Kerns RD. Meta-analysis of psychological interventions for chronic low back pain. Health Psychol 2007;26:1-9.

7. Andersson $G$, Cuijpers $P$. Pros and cons of online cognitivebehavioural therapy. Br J Psychiatry 2008;193:270-1.

8. Griffiths F, Lindenmeyer A, Powell J, Lowe P, Thorogood M. Why are health care interventions delivered over the internet? A systematic review of the published literature. J Med Internet Res 2006;8:e10.

9. Andrews G, Cuijpers P, Craske MG, McEvoy P, Titov N. Computer therapy for the anxiety and depressive disorders is effective, acceptable and practical health care: a meta-analysis. PLoS One 2010;5:e13196.

10. Arnberg FK, Linton SJ, Hultcrantz M, Heintz E, Jonsson U. Internet-delivered psychological treatments for mood and anxiety disorders: a systematic review of their efficacy, safety, and cost-effectiveness. PLoS One 2014;9:e98118.

11. Barak A, Hen L, Boniel-Nissim M, Shapira N. A comprehensive review and a meta-analysis of the effectiveness of internetbased psychotherapeutic interventions. J Tech Hum Serv 2008; 26:109-60.

12. Calear AL, Christensen $H$. Review of internet-based prevention and treatment programs for anxiety and depression in children and adolescents. Med J Aust 2010;192:S12-4.

13. Griffiths KM, Christensen H. Review of randomised controlled trials of Internet interventions for mental disorders and related conditions. Clin Psychol 2006;10:16-29.

14. Hedman E, Ljótsson B, Lindefors N. Cognitive behavior therapy via the Internet: a systematic review of applications, clinical efficacy and cost-effectiveness. Expert Rev Pharmacoecon Outcomes Res 2012;12:745-64.

15. Christensen H, Griffiths KM, Mackinnon AJ, Brittliffe K. Online randomized controlled trial of brief and full cognitive behaviour therapy for depression. Psychol Med 2006;36:1737-46.

16. Postel MG, Haan HA de, Jong CA de. E-therapy for mental health problems: a systematic review. Telemed J E Health 2008; 14:707-14.

17. Spek V, Cuijpers P, Nyklìcek I, Riper H, Keyzer J, Pop V. Internetbased cognitive behaviour therapy for symptoms of depression and anxiety: a meta-analysis. Psychol Med 2007;37:319-28.

18. Wade AG. Use of the internet to assist in the treatment of depression and anxiety: a systematic review. Prim Care Companion J Clin Psychiatry 2010;12. 
19. Andersson G, Ljótsson B, Weise C. Internet-delivered treatment to promote health. Curr Opin Psychiatry 2011;24:168-72.

20. Bender JL, Radhakrishnan A, Diorio C, Englesakis M, Jadad AR. Can pain be managed through the Internet? A systematic review of randomized controlled trials. Pain 2011;152:1740-50.

21. Cuijpers P, Straten A van, Andersson G. Internet-administered cognitive behavior therapy for health problems: a systematic review. J Behav Med 2008;31:169-77.

22. Eland-de Kok P, Os-Medendorp H van, Vergouwe-Meijer A, Bruijnzeel-Koomen $C$, Ros W. A systematic review of the effects of e-health on chronically ill patients. J Clin Nurs 2011;20: 2997-3010.

23. Macea DD, Gajos K, Daglia Calil YA, Fregni F. The efficacy of web-based cognitive behavioral interventions for chronic pain: a systematic review and meta-analysis. J Pain 2010;11:917-29.

24. Stinson J, Wilson R, Gill N, Yamada J, Holt J. A systematic review of internet-based self-management interventions for youth with health conditions. J Pediatr Psychol 2009;34:495-510.

25. Wantland DJ, Portillo CJ, Holzemer WL, Slaughter R, McGhee $E M$. The effectiveness of Web-based vs. non-Web-based interventions: a meta-analysis of behavioral change outcomes. J Med Internet Res 2004;6:e40.

26. Webb TL, Joseph J, Yardley L, Michie S. Using the internet to promote health behavior change: a systematic review and meta-analysis of the impact of theoretical basis, use of behavior change techniques, and mode of delivery on efficacy. J Med Internet Res 2010;12:e4.

27. Andersson G, Cuijpers P. Internet-based and other computerized psychological treatments for adult depression: a metaanalysis. Cogn Behav Ther 2009;38:196-205.

28. Beugen $S$ van, Ferwerda $M$, Hoeve D et al. Internet-based cognitive behavioral therapy for patients with chronic somatic conditions: a meta-analytic review. J Med Internet Res 2014;16:e88.

29. Anderson $G$. Chronic care: making the case for ongoing care. 2010. Available from: http://www.rwjf.org/content/dam/farm/ reports/reports/2010/rwjf54583.

30. Abbott JA, Kaldo V, Klein B et al. A cluster randomised trial of an internet-based intervention program for tinnitus distress in an industrial setting. Cogn Behav Ther 2009;38:162-73.

31. Andersson G, Lundström P, Ström L. Internet-based treatment of headache: does telephone contact add anything? Headache 2003; 43:353-61.

32. Andersson G, Strömgren T, Ström L, Lyttkens L. Randomized controlled trial of internet-based cognitive behavior therapy for distress associated with tinnitus. Psychosom Med 2002;64: 810-16.

33. Berman RL, Iris MA, Bode R, Drengenberg C. The effectiveness of an online mind-body intervention for older adults with chronic pain. J Pain 2009;10:68-79.

34. Brattberg $G$. Internet-based rehabilitation for individuals with chronic pain and burnout: a randomized trial. Int J Rehabil Res 2006;29:221-27.

35. Buhrman M, Fältenhag S, Ström L. Controlled trial of Internetbased treatment with telephone support for chronic back pain. Pain 2004;111:368-77.

36. Buhrman M, Nilsson-Ihrfeldt E, Jannert M, Ström L, Andersson G. Guided internet-based cognitive behavioural treatment for chronic back pain reduces pain catastrophizing: A randomized controlled trial. J Rehabil Med 2011;43:500-5.

37. David N, Schlenker P, Prudlo U, Larbig W. Online counseling via e-mail for breast cancer patients on the German internet: preliminary results of a psychoeducational intervention. Psychosoc Med 2011;8:doc05.

38. Devineni T, Blanchard EB. A randomized controlled trial of an internet-based treatment for chronic headache. Behav Res Ther 2005;43:277-92.

39. Ghahari S, Leigh PT, Passmore AE. Effectiveness of an online fatigue self-management programme for people with chronic neurological conditions: a randomized controlled trial. Clin Rehabil 2010;24:727-44.

40. Hedborg K, Muhr C. Multimodal behavioral treatment of migraine: an Internet-administered, randomized, controlled trial. Ups J Med Sci 2011;116:169-86.

41. Hesser H, Gustafsson T, Lundén C et al. A randomized controlled trial of internet-delivered cognitive behavior therapy and acceptance and commitment therapy in the treatment of tinnitus. J Consult Clin Psychol 2012;80:649-61.

42. Hunt MG, Moshier S, Milonova M. Brief cognitive-behavioral internet therapy for irritable bowel syndrome. Behav Res Ther 2009; 47: 797-802.

43. Kaldo V, Levin S, Widarsson J, Buhrman M, Larsen HC, Andersson $G$. Internet versus group cognitive-behavioral treatment of distress associated with tinnitus: a randomized controlled trial. Behav Ther 2008;39:348-59.

44. Ljótsson B, Andersson G, Andersson E et al. Acceptability, effectiveness, and cost-effectiveness of internet-based exposure treatment for irritable bowel syndrome in a clinical sample: a randomized controlled trial. BMC Gastroenterol 2011;11:110.

45. Ljótsson B, Falk L, Vesterlund AW et al. Internet-delivered exposure and mindfulness based therapy for irritable bowel syndrome-a randomized controlled trial. Behav Res Ther 2010; 48:531-39.

46. Ljótsson B, Hedman E, Andersson E et al. Internet-delivered exposure-based treatment vs. stress management for irritable bowel syndrome: a randomized trial. Am J Gastroenterol 2011; 106:1481-91.

47. Lorig K, Ritter PL, Laurent DD et al. Online diabetes selfmanagement program: a randomized study. Diabetes Care 2010;33:1275-81.

48. Lorig KR, Ritter PL, Laurent DD, Plant K. Internet-based chronic disease self-management: a randomized trial. Med Care 2006;44:964-71.

49. Lorig KR, Ritter PL, Laurent DD, Plant K. The internet-based arthritis self-management program: a one-year randomized trial for patients with arthritis or fibromyalgia. Arthritis Rheum 2008;59:1009-17.

50. Ström L, Pettersson R, Andersson G. A controlled trial of selfhelp treatment of recurrent headache conducted via the Internet. J Consult Clin Psychol 2000;68:722-7.

51. Thompson NJ, Walker ER, Obolensky $N$ et al. Distance delivery of mindfulness-based cognitive therapy for depression: Project UPLIFT. Epilepsy Behav 2010;19:247-54.

52. Bastelaar KM van, Pouwer F, Cuijpers P, Riper H, Snoek FJ. Webbased depression treatment for type 1 and type 2 diabetic patients: a randomized, controlled trial. Diabetes Care 2011;34:320-25.

53. Morris $S B$. Estimating effect sizes from pre-test-posttest-control group design. Organizational Research Methods 2008;11: 364-86.

54. Cohen J. Statistical power analysis for the behavioral sciences. Hillsdale, NJ: Erlbaum, 1988. 
55. Higgins JP, Thompson SG, Deeks JJ, Altman DG. Measuring inconsistency in meta-analyses. BMJ 2003;327:557-60.

56. Hedges $L V$, Vevea JL. Fixed- and random effects models in meta-analysis. Psychol Methods 2011;3:486-504.

57. Cheng SK, Dizon J. Computerised cognitive behavioural therapy for insomnia: a systematic review and meta-analysis. Psychother Psychosom 2012;81:206-16.

58. Beltman MW, Voshaar RC, Speckens AE. Cognitive-behavioural therapy for depression in people with a somatic disease: metaanalysis of randomised controlled trials. Br J Psychiatry 2010; 197:11-19.

59. Hesser H, Weise C, Westin VZ, Andersson G. A systematic review and meta-analysis of randomized controlled trials of cognitivebehavioral therapy for tinnitus distress. Clin Psychol Rev 2011; 31:545-53.

60. Tate DF, Finkelstein EA, Khavjou O, Gustafson A. Cost effectiveness of internet interventions: review and recommendations. Ann Behav Med 2009;38:40-5.

61. Musiat P, Tarrier N. Collateral outcomes in e-mental health: a systematic review of the evidence for added benefits of computerized cognitive behavior therapy interventions for mental health. Psychol Med 2014;15:3137-50.

62. Andersson E, Ljótsson B, Smit F et al. Cost-effectiveness of internet-based cognitive behavior therapy for irritable bowel syndrome: results from a randomized controlled trial. BMC Public Health 2011;11:215.

63. Boer MJ, Versteegen GJ, Vermeulen KM, Sanderman R, Struys $M M R F$. A randomized controlled trial of an Internet-based cognitive-behavioural intervention for non-specific chronic pain: An effectiveness and cost-effectiveness study. Europ J Pain 2014, in press.

64. Kaldo V, Levin S, Widarsson J, Buhrman M, Larsen HC, Andersson $G$. Internet versus group cognitive-behavioral treatment of distress associated with tinnitus: a randomized controlled trial. Behavior Therapy 2008;39:348-59.

65. Moss-Morris R, McCrone P, Yardley L, van Kessel K, Wills G, Dennilson L. A pilot randomised controlled trial of an Internetbased cognitive behavioural therapy self-management programme (MS Invigor8) for multiple sclerosis fatigue. Behav Res Ther 2012;50:415-21.

66. Johansson R, Andersson G. Internet-based psychological treatments for depression. Expert Rev Neurother 2012;12:861-70.

67. Robinson E, Titov N, Andrews G, McIntyre K, Schwencke G, Solley, $K$. Internet treatment for generalized anxiety disorder: a randomized controlled trial comparing clinician vs. technician assistance. PloS one 2010;5:e10942.

68. Titov N, Andrews G, Davies M, McIntyre K, Robinson E, Solley $K$. Internet treatment for depression: a randomized controlled trial comparing clinician vs. technician assistance. PloS one 2010;5:e10939.

69. Evers AWM, Gieler U, Hasenbring MI, Middendorp $H$ van. Incorporating biopsychosocial characteristics into personalized healthcare: a clinical approach. Psychother Psychosom 2014; 83:148-57.

70. Vaart R van der, Witting M, Riper H, Kooistra L, Bohlmeijer ET, Gemert-Pijnen LJEWC van. Blending online therapy into regular face-to-face therapy for depression: content, ratio and preconditions according to patients and therapists using a Delphi study. BMC Psychiatry, in press.
71. Ballegooijen W van, Cuijpers P, Straten A van, Karyotaki E, Andersson G, Smit JH, Riper H. Adherence to Internet-based and face-to-face cognitive behavioural therapy for depression: a meta-analysis. PLoS One 2014;9:e100674.

72. Shapiro DA, Barkham M, Rees A, Hardy GE, Reynolds S, Startup $M$. Effects of treatment duration and severity of depression on the effectiveness of cognitive-behavioral and psychodynamic-interpersonal psychotherapy. J Consult Clin Psychol 1994;62:522-34.

73. Nationale Implementatie Agenda eHealth. Juni 2012.

74. Schippers EI. M.v.V., Welzijn en Sport, Kamerbrief. 7 juni 2012.

75. Chaudhry B, Wang J, Wu S, Maglione M, Mojica W, Roth E, Morton SC, Shekelle PG. Systematic review: impact of health information technology on quality, efficiency, and costs of medical care. Ann Int Med 2006;144:742-52.

76. Gemert-Pijnen JE van, Nijland N, Limburg M van, Ossebaard HC, Kelders SM, Eysenbach G, Seydel ER. A holistic framework to improve the uptake and impact of eHealth technologies. J Med Internet Res 2011;13:e111.

77. Vaart $R$ van der. Rheumatology 2.0: empowering patients by eHealth. Doctoral dissertation: University of Twente, the Netherlands; 2013.

78. Eysenbach $G$. The law of attrition. J Med Internet Res 2005;7:e11.

79. Couper MP, Alexander GL, Zhang $N$ et al. Engagement and retention: measuring breadth and depth of participant use of an online intervention. J Med Internet Res 2010;12:e52.

80. Morrison LG, Yardley L, Powell J, Michie S. What design features are used in effective e-health interventions? A review using techniques from Critical Interpretive Synthesis. Telemed J E Health 2012;18:137-44

81. Schubart JR, Stuckley HL, Ganeshamoorthy A, Sciamanna CN. Chronic health conditions and internet behavioral interventions: a review of factors to enhance user engagement. Comput Inform Nurs 2011;29:81-92.

82. Kelders SM, Ossebaard HC, Gemert-Pijnen JE van. Persuasive system design does matter: a systematic review of adherence to web-based interventions. J Med Internet Res 2012;14:e152.

83. Brouwer W, Kroeze W, Crutzen R, Nooijer J de, Vries NK de, Brug $J$, Oenema $A$. Which intervention characteristics are related to more exposure to internet-delivered healthy lifestyle promotion interventions? A systematic review. J Med Internet Res 2011;13:e2.

84. Danaher BG, Seeley JR. Methodological issues in research on webbased behavioral interventions. Ann Behav Med 2009;38:28-39.

85. Sowan AK, Jenkins LS. Paradata: a new data source from webadministered measures. Comput Inform Nurs 2010;28:333-42.

86. Barak A, Grohol JM. Current and future trends in Internetsupported mental health interventions. J Technol Hum Serv 2011;29:155-96.

87. Malloy KM, Milling LS. The effectiveness of virtual reality distraction for pain reduction: a systematic review. Clin Psychol Rev 2010;30:1011-8.

\section{CORRESPONDENTIEADRES}

Mw. drs. S. van Beugen, Sectie Gezondheids-, Medische en Neuropsychologie, Instituut Psychologie, Faculteit der Sociale Wetenschappen, Universiteit Leiden, Postbus 9555, 2300 RB Leiden, tel. 071-5274047, e-mail: s.van.beugen@fsw.leidenuniv.nl 